\title{
An improved active frequency drift anti-islanding method for multiple PV micro-inverter systems
}

\author{
Byunggyu $\mathbf{Y u}^{\mathrm{a})}$ \\ Division of Electrical, Electronics and Control Engineering, Kongju National \\ University, 1223-24, Cheonan Daero, Seobuk-gu, Cheonan-si, Chungnam, 331- \\ 717, Korea \\ a)bgyuyu@kongju.ac.kr
}

\begin{abstract}
Islanding phenomenon of Photovoltaic (PV) system should be prevented because it causes a safety problem to utility service personnel and power supply facilities. Until now, various antiislanding methods have been proposed. However, these are mostly focus on the islanding prevention method for single PV system. Recently, PV system using micro-inverters are widely disseminated in the field. Accordingly, an islanding issue for multiple PV microinverter systems has been paid attention due to their interaction not to detect islanding, even though the single micro-inverter unit can prevent islanding when the single unit is only tested. This paper presents an improved active frequency drift (AFD) anti-islanding method for multiple PV micro-inverter systems. The proposed method injects every half-line cycle asymmetrical signals and uses the correlation between the injected asymmetrical signal and the corresponding half line cycle. The proposed method is verified by using PSIM simulation, compared with the conventional AFD method. It shows that the proposed method is highly effective to detect islanding even under multiple micro-inverter system while the conventional one doesn't detect islanding.
\end{abstract}

Keywords: PV power generation, anti-islanding, islanding detection method, PV inverter, PV micro-inverter

Classification: Electron devices, circuits, and systems

\section{References}

[1] M. E. Ropp, M. Begovi and A. Rohatgi: IEEE Trans. Energy Convers. 14 (1999) 810.

[2] L. A. C. Lopes and H. Sun: IEEE Trans. Energy Convers. 21 (2006) 171.

[3] L. A. C. Lopes and Y. Zhang: IEEE Trans. Power Del. 23 (2008) 480.

[4] H. H. Zeineldin and M. M. A. Salama: IEEE Trans. Ind. Electron. 58 (2011) 139.

[5] S. I. Jang and K. H. Kim: IEEE Trans. Power Del. 19 (2004) 745.

[6] J. C. M. Vieira, D. S. Correa, W. Freitas and W. Xu: IEEE Trans. Power Syst. 20 (2005) 1660. 
[7] B. Yu, M. Matsui and G. Yu: IEEE Trans. Ind. Electron. 58 (2011) 2935.

[8] A. Yafaoui, B. Wu and S. Kouro: IEEE Trans. Power Electron. 27 (2012) 2367.

[9] B. Yu, M. Matsui and G. Yu: Solar Energy 84 (2010) 745.

[10] IEEE Standard 1547.1 (2005) 27.

\section{Introduction}

In modern electric power system, photovoltaic generation as one of the prominent renewable energy sources has been growing larger and more complicated [1]. However, the advent of rapidly growing photovoltaic systems makes some problems to the stability and the power quality in the adjacent utility. Especially, as shown in Fig 1, the most issued problem is islanding phenomenon of grid-connected inverter which is defined as an independent power generation while the utility is disconnected $[2,3]$. Islanding causes a number of undesirable effects like safety hazard to utility service personnel and equipment malfunction [4].

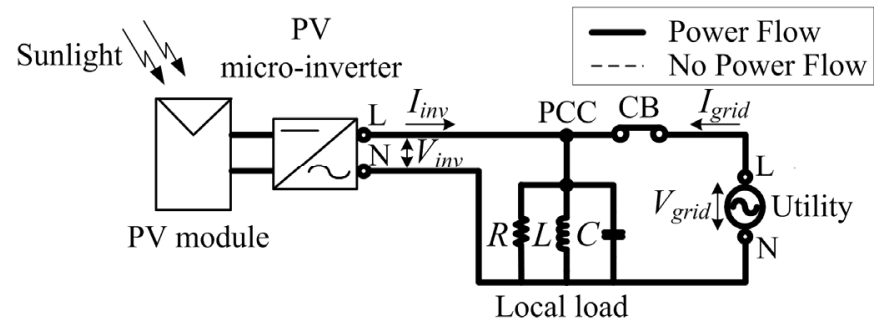

(a)

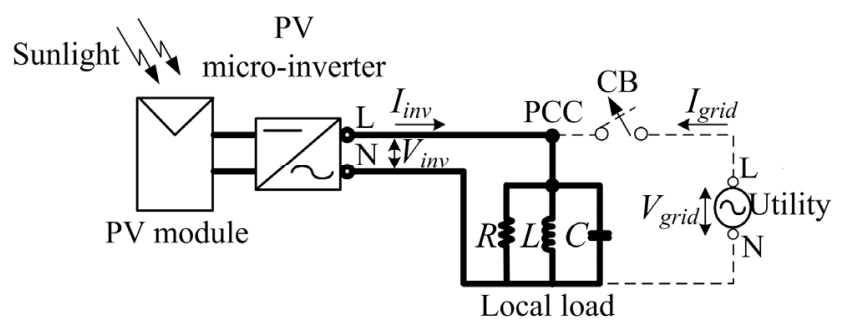

(b)

Fig. 1. Single PV micro-inverter system configuration. (a) Grid-connected mode. (b) Islanding phenomenon mode.

In order to prevent islanding, a lot of anti-islanding methods have been studied $[4,5,6,7,8,9]$. Among them, passive methods depends on the voltage monitoring only at point of common coupling to detect islanding [4, 5], while active methods inject active signals intentionally in the PV inverter output to detect islanding $[6,7,8,9]$. Since passive methods couldn't detect islanding when PV power and local load power are matched, active methods are essential for PV to detect islanding [9].

Until now, various active anti-islanding methods have been proposed [9]. However, these are mostly focus on the islanding prevention method for single PV system. Recently, PV system using micro-inverters are widely disseminated in the field. Accordingly, an islanding issue for 
multiple PV micro-inverter systems has been paid attention due to their interaction not to detect islanding, even though the single micro-inverter unit can prevent islanding when the single unit is only tested [9]. This paper presents an improved active frequency drift (AFD) anti-islanding method for multiple single phase PV micro-inverter systems. The proposed method injects every half-line cycle asymmetrical signals and uses the correlation between the injected asymmetrical signal and the corresponding half line cycle. The proposed method is verified by using PSIM simulation, compared with the conventional AFD method.

\section{The conventional AFD method overview}

The conventional AFD method is implemented by injecting the disturbance signal into PV inverter output current. In Fig 2, the key parameter of the conventional AFD method is chopping fraction $(c f)$ defined as the ratio of the zero time $\left(t_{z}\right)$ to half of the period of the voltage waveform $\left(T_{1} / 2\right)$ as follows $[1,2,3,8,9]$.

$$
c f=\frac{t_{z}}{\left(T_{1} / 2\right)}
$$

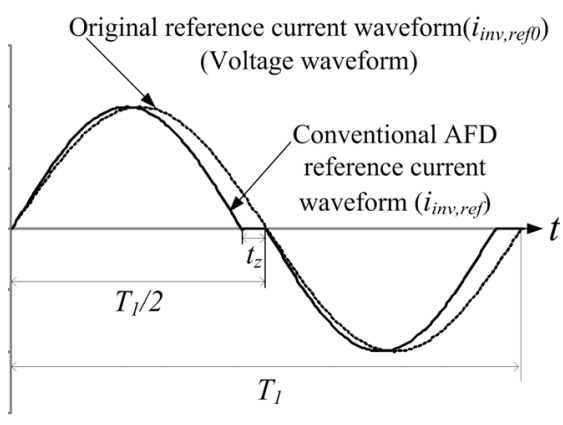

(a)

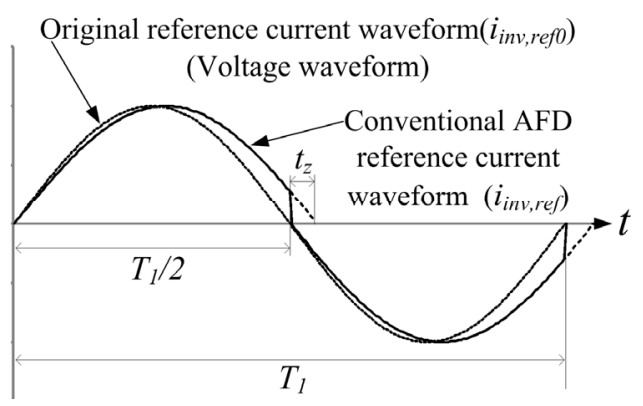

(b)

Fig. 2. Current $\left(i_{\text {inv }}\right)$ reference waveform of PV microinverter using conventional AFD method. (a) Based on positive chopping fraction. (b) Based on negative chopping fraction.

In order to increase the islanding detection capability, the disturbance should be higher. However, this disturbance causes the low power quality by increasing the current harmonic components. Thus, it is very important to design the disturbance optimally with high islanding detection capability and low harmonics.

The conventional AFD method is widely used in the commercial PV power conditioning system (PCS). Before islanding occurs, the frequency of micro-inverter output voltage will be maintained by the solid utility voltage source. However, while islanding occurs, the conventional AFD method causes to drift for the frequency to the threshold value of over frequency relay (OFR) and under frequency relay (UFR). When the chopping fraction is positive as shown in Fig. 2 (a), the frequency of micro-inverter output voltage will be increased to the threshold value of OFR after islanding occurs. In the same way, when the chopping fraction is negative as shown in Fig. 2 (b), the frequency will be decreased to the threshold 
value of UFR after islanding. Thus, islanding is prevented by using the conventional AFD method. In other words, it depends on the frequency relay to detect islanding by drifting the frequency under different chopping fraction. This conventional AFD method is effective for resistive loads but doesn't detect islanding under multiple micro-inverter systems because the power variation by different chopping fraction can be cancelled out by interacting between multiple micro-inverter systems.

\section{The improved AFD method}

\subsection{A novel AFD reference current waveform}

The improved AFD method uses two different chopping fractions every half-line cycle while the conventional one use single chopping fraction every whole line cycle. This means that the proposed chopping fraction can break the resonance at the frequency of whole line cycle. Fig. 3 shows the proposed AFD reference current waveforms with two different chopping fractions: One is positive and the other is negative every half-line cycle. The proposed AFD reference current waveform in Fig. 3 can be defined as:

$i_{i n v, r e f}(t)= \begin{cases}I_{p k, p} \sin \left(2 \pi f_{1 p} \cdot t\right) & \leftarrow 0 \leq t \angle\left(T_{a}-t_{z}\right) \\ 0 & \leftarrow\left(T_{a}-t_{z}\right) \leq t \angle T_{a} \\ I_{p k, n} \sin \left(2 \pi f_{1 n} \cdot\left(t-T_{a}\right)+\pi\right) & \leftarrow T_{a} \leq t \angle\left(T_{a}+T_{b}-t_{z}\right) \\ 0 & \leftarrow t=\left(T_{a}+T_{b}-t_{z}\right)\end{cases}$

where the original reference current $i_{\text {inv,refo }}(t)=I_{p k, 0} \sin \left(2 \pi f_{1} t\right), f_{1 p}=f_{1}(1 /$ $\left.\left(1-c f_{p}\right)\right), f_{1 n}=f_{1}\left(1 /\left(1-c f_{n}\right)\right)$ with positive chopping fraction $c f_{p}=\left(t_{z} / T_{a}\right)$ and negative chopping fraction $c f_{n}=-\left(t_{z} / T_{b}\right)$.

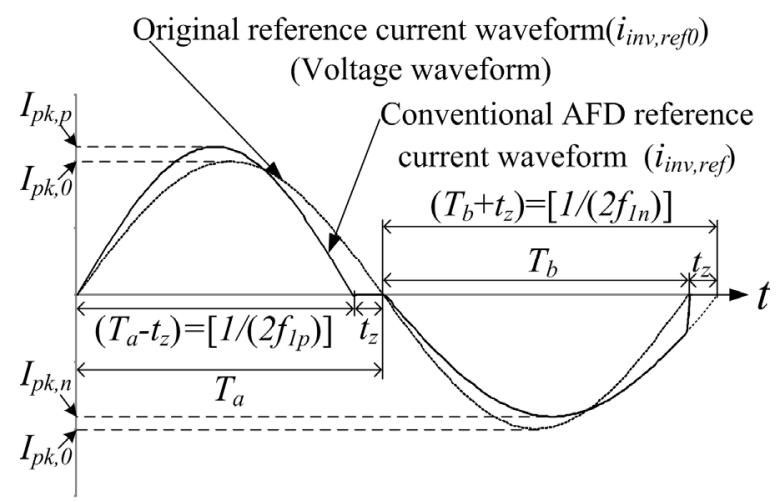

Fig. 3. Operational current waveform of the proposed AFD method.

In the paper, the applied chopping fraction magnitude between $c f_{p}$ and $c f_{n}$ are the same with different signs. For this proposed AFD method, the peak values $I_{p k, p}$ and $I_{p k, n}$ of the reference current should be different from the peak value $I_{p k, 0}$ of the original reference current. Otherwise, DC component of the micro-inverter output AC current will be generated and it could be a serious problem to the utility side such as transformer saturation. In order to remove the DC component, the average value between the original reference current waveform and the proposed AFD reference current waveform in Fig. 3 should be the same.

Before islanding occurs, the half-line cycle of the micro-inverter voltage 
should be the same like $T_{a}=T_{b}=\left(T_{1} / 2\right)$ in Fig. 3 because the frequency is maintained by the solid utility voltage source. Thus, the average value of original reference current $i_{\text {inv,refo }}$ for the half line cycle is calculated as

$$
I_{a v g, 0}=\int_{0}^{\frac{T_{1}}{2}} I_{p k, 0} \sin \left(2 \pi f_{1} t\right) d t=\int_{\frac{T_{1}}{2}}^{T_{1}} I_{p k, 0} \sin \left(2 \pi f_{1} t\right) d t
$$

The average value of AFD reference current $i_{\text {inv,ref }}$ for the half line cycle is also derived as

$$
\int_{0}^{\frac{T_{1}}{2}} I_{p k, p} \sin \left(2 \pi f_{1 p} t\right) d t=\int_{\frac{T_{1}}{2}}^{T_{1}} I_{p k, n} \sin \left(2 \pi f_{1 n}\left(t-\frac{T_{1}}{2}\right)+\pi\right) d t
$$

From (2) to (3), the new peak value of the AFD reference current can be calculated as

$$
\begin{aligned}
& I_{p k, p}=\frac{I_{p k, 0}}{1-c f_{p}} \\
& I_{p k, n}=\frac{I_{p k, 0}}{1-c f_{n}}
\end{aligned}
$$

\subsection{Operational principle using correlation parameter}

Before islanding occurs, the half-line cycle of the micro-inverter output voltage will be maintained by the solid utility voltage source. However, after islanding occurs, the half-line cycle of the micro-inverter output AC voltage will be determined by the proposed AFD reference current in section 3.1. This relation can be quantized by using the proposed correlation parameter as (6).

$$
C_{P}[i]=\sum_{k=i-N}^{i-1}\left(\left(2 \cdot f_{1 p}[k]\right) \times c f_{p}[k]+\left(2 \cdot f_{1 n}[k]\right) \times c f_{n}[k]\right)
$$

where $C_{P}[i]$ is the correlation parameter at the $i^{\text {th }}$ instance, $N$ is the observing line cycles to calculate the correlation parameter, $f_{1 p}[k] / f_{1 n}[k]$ are the measured positive/negative half-line frequencies of the micro-inverter output voltage in Fig. 3, and $c f_{\mathrm{p}} / c f_{n}$ are positive/negative chopping fractions as the perturbation ratio to the nominal current command.

The proposed islanding detection method is based on the correlation technique between the proposed AFD current waveform and the corresponding half line period of the micro-inverter voltage. The proposed method uses the fact that the frequency of PV micro-inverter voltage has a strong correlation with the current frequency deviation when islanding occurs. On the other hand, when the grid is connected, micro inverter voltage is dominated by the rigid grid voltage source and it has a weak correlation with the proposed AFD reference current frequency perturbation. In other words, it doesn't depend on the frequency relay like OFR and UFR, but relies on the correlation parameter between injected signal and the corresponding half line period as equation (6). This means that islanding can be detected by using the proposed correlation parameter more efficiently in addition to the frequency relay.

Fig. 4 depicts the operational flow chart of the proposed method. It 


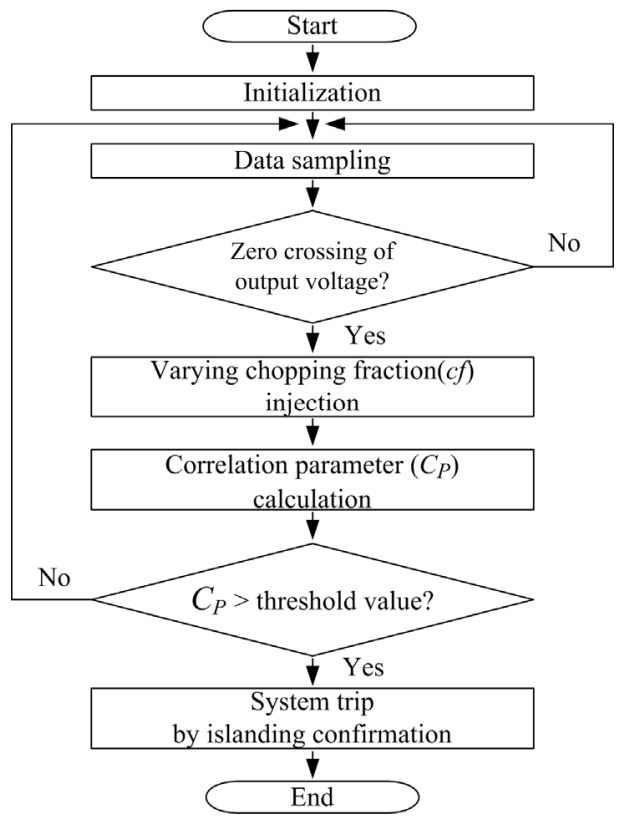

Fig. 4. Flowchart of the proposed AFD method.

consists of zero crossing by PLL (phase locked loop), periodic current magnitude perturbation, correlation parameter calculation, and decision process. Simply, the concept of the proposed method is based on the fact that the islanding situation can be determined if the calculated correlation factor in (6) is higher than the threshold reference value, because frequency of the inverter output voltage has strong correlation with the inverter current frequency under islanding. Based on the proposed correlation factor equation (6), the key operational waveforms for islanding detection are shown in Fig. 5.

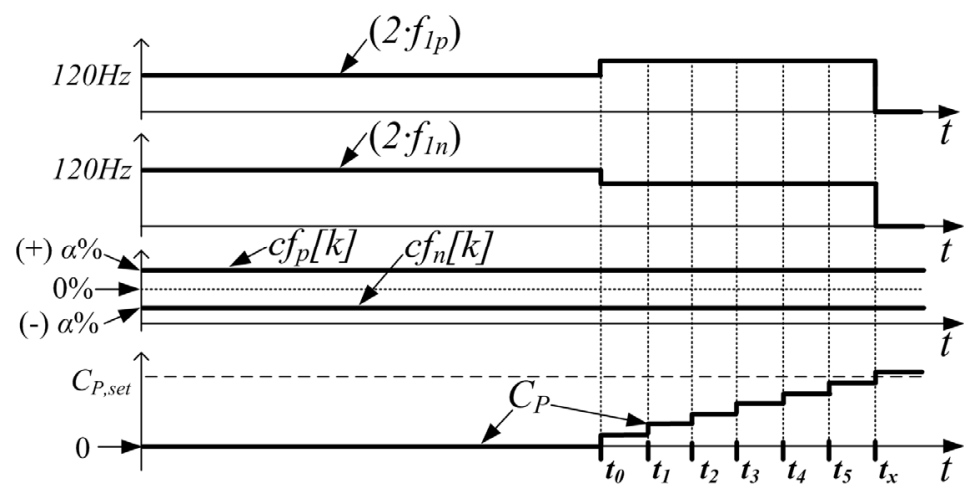

Fig. 5. Main operational waveforms of the proposed AFD method including positive half line frequency $\left(2 \cdot f_{1 p}\right)$, negative half line frequency $\left(2 \cdot f_{1 n}\right)$, injected chopping fraction $c f_{p}, c f_{n}$, and correlation parameter $C_{P}$.

Unlike the conventional AFD method, the proposed method is very effective to detect under multiple PV micro-inverter system because there are no cancellation effect among micro-inverter system by using the halfline cycle of the utility voltage as a reference. As shown in Fig. 3 and Fig. 6, the positive chopping fraction $c f_{p}$ is always injected into positive half line cycle of $v_{\text {grid }}$ and the negative chopping fraction $c f_{n}$ is injected into negative 


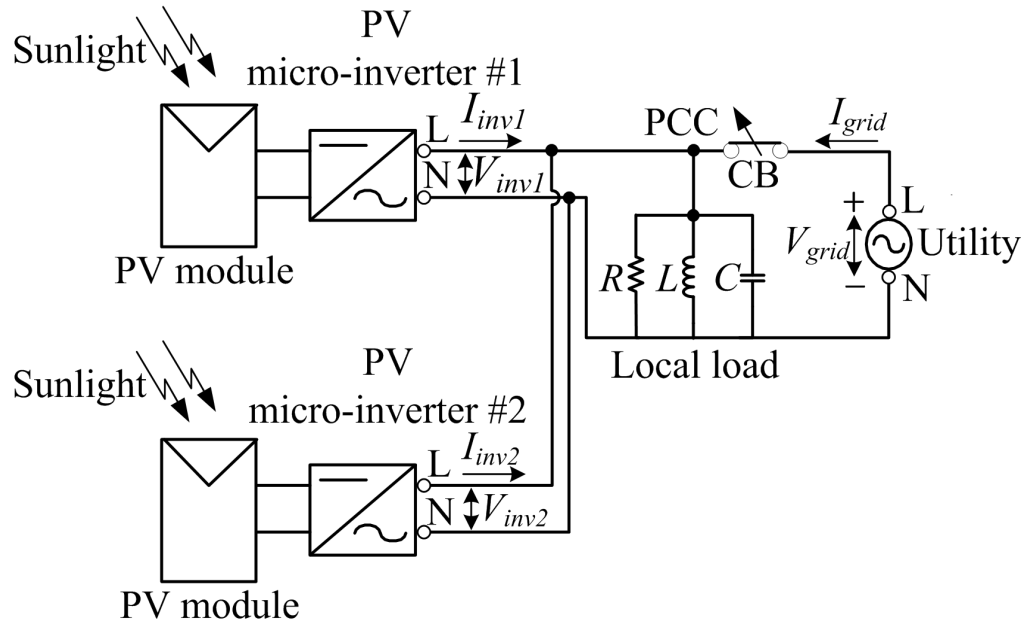

Fig. 6. Two PV micro-inverter systems for islanding detection test.

half line cycle of $v_{\text {grid }}$ for both micro inverter \#1 and micro inverter \#2. Thus, the injected signals are not cancelled out.

\section{Simulated results}

The simulated result of the proposed AFD method by using PSIM software was performed in order to verify the islanding detection capability and operation under abnormal grid condition, especially for multiple PV microinverter systems. Simulation is based on the circuit parameters shown in Table I. The magnitude of the proposed chopping fraction $c f$ is set as $2.5 \%$ and the threshold correlation parameter to judge islanding is determined as 0.25 based on the following analysis.

Table I. System parameters for simulation.

\begin{tabular}{|c|c|c|}
\hline Parameter & \multicolumn{2}{|c|}{ Value } \\
\hline Local load $R, L, C$ power & Quality factor $Q_{f}=1$ & $\begin{array}{l}P_{R}=350[\mathrm{~W}] \\
Q_{L}=350[\mathrm{Var}] \\
Q_{C}=350[\mathrm{Var}]\end{array}$ \\
\hline Chopping fraction (Proposed method), $c f$ & \multicolumn{2}{|c|}{$-2.5 \% \sim 2.5 \%$} \\
\hline $\begin{array}{l}\text { Threshold value of Correlation parameter, } \\
\qquad C_{P, s e t}\end{array}$ & \multicolumn{2}{|c|}{0.25} \\
\hline Single micro inverter nominal power, $P_{i n v}$ & \multicolumn{2}{|c|}{$350 \mathrm{~W}$} \\
\hline Nominal grid voltage, frequency, $V_{\text {grid }}$ & \multicolumn{2}{|c|}{$220 \mathrm{~V}, 60 \mathrm{~Hz}$, single phase } \\
\hline Normal frequency range, $f$ & \multicolumn{2}{|c|}{$59.3 \mathrm{~Hz} \leq f \leq 60.5 \mathrm{~Hz}$} \\
\hline Normal voltage range, $V$ & \multicolumn{2}{|c|}{$88 \% \leq V \leq 110 \%$} \\
\hline
\end{tabular}

If the nominal grid frequency is determined by $60 \mathrm{~Hz}$ with $2.5 \%$ chopping fraction in Table I, the islanding frequency $f_{1 p}$ and $f_{1 n}$ can be calculated as around $61.538 \mathrm{~Hz}$ and $58.536 \mathrm{~Hz}$ from equation (1). According to equation (6), the correlation parameter is around 0.75 with $N=5$ line period calculation. Practically, the calculated value has frequency sensing errors in digital controller and some transient responses for $L C$ resonance. Thus, after applying margin, the threshold value of the correlation parameter in this paper is chosen as 0.25 , which is around $30 \%$ of the calculated correlation parameter. The $R, L, C$ parameters like load power $P_{R}, Q_{L}$, and $Q_{C}$ in Fig. 1 and Fig. 6 are designed by the quality factor $Q_{f}$ 
definition by equation (7) [10]. The IEEE 1547 standard requires $R, L, C$ resonance local load condition with unity quality factor [1]. In this simulation, the islanding detection test conducted under unity quality

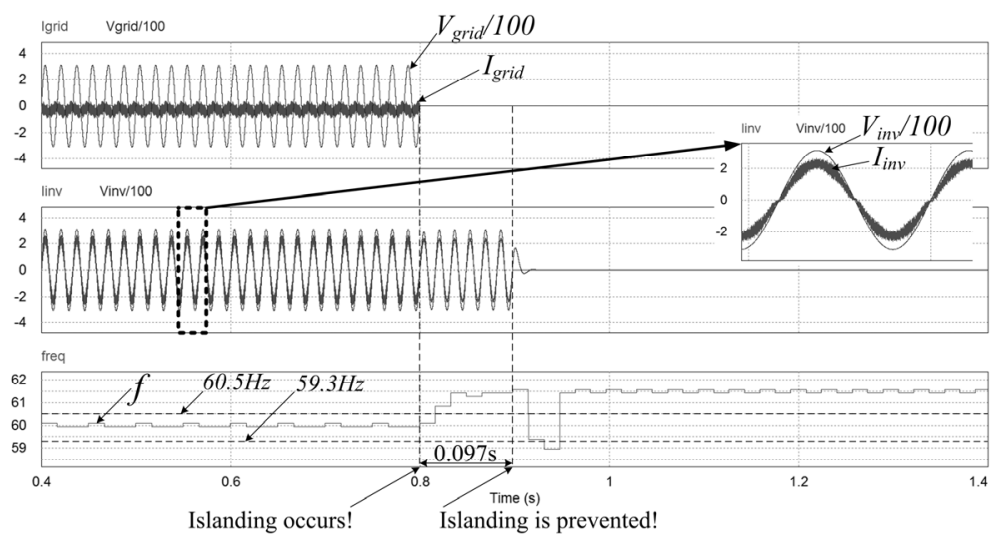

(a)

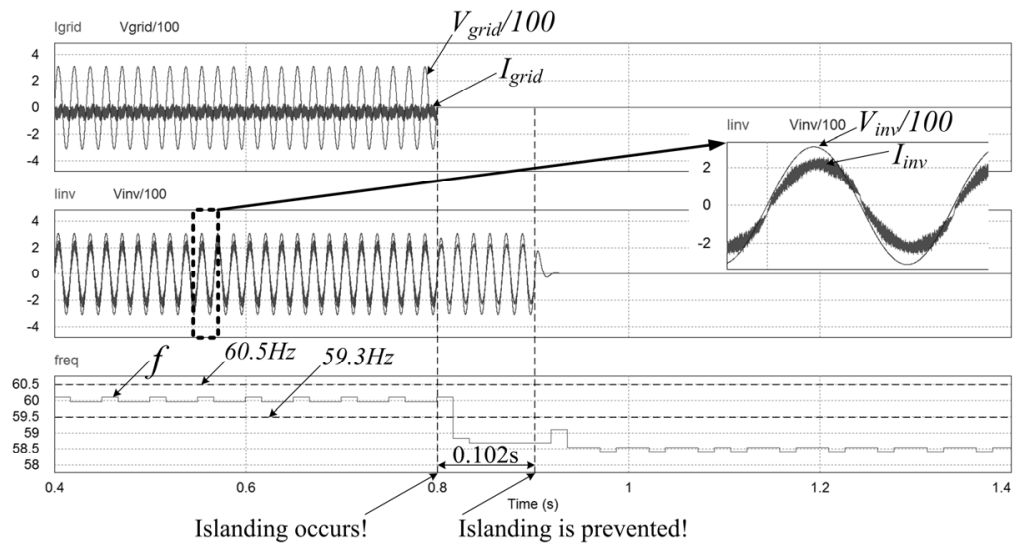

(b)

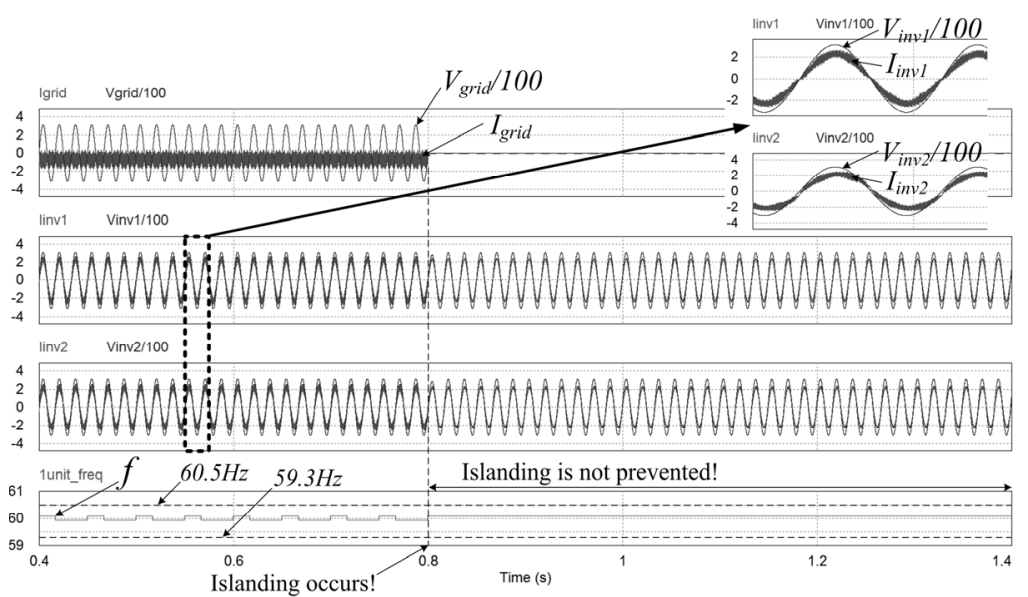

(c)

Fig. 7. Anti-islanding test results by using the conventional AFD method under unity quality factor local resonant load. (a) $+5 \%$ chopping fraction injection for single micro inverter. (b) $-5 \%$ chopping fraction injection for single micro inverter. (c) $+5 \%$ chopping fraction injection for one micro inverter and $-5 \%$ chopping fraction injection for the other micro inverter. 
factor.

$$
Q_{f}=R \sqrt{\frac{C}{L}}=\frac{Q_{L} \times Q_{C}}{P_{R}}
$$

As shown in Fig. 7, the conventional AFD method was implemented and tested in the simulation with $\pm 5 \%$ chopping fraction. Anti-islanding test for a single micro inverter was conducted as Fig. 1, which was introduced in IEEE Std. 1547 and anti-islanding test for two-unit microinverter systems was implemented as Fig. 6. As a single unit anti-islanding test result, Fig. 7 (a) shows the waveforms of grid voltage $\left(V_{\text {grid }}\right)$, grid

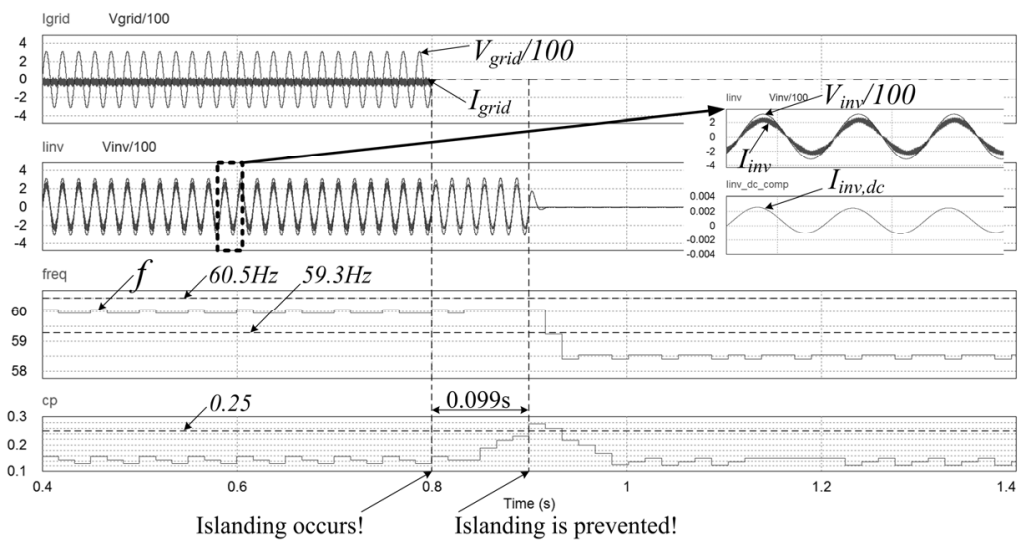

(a)

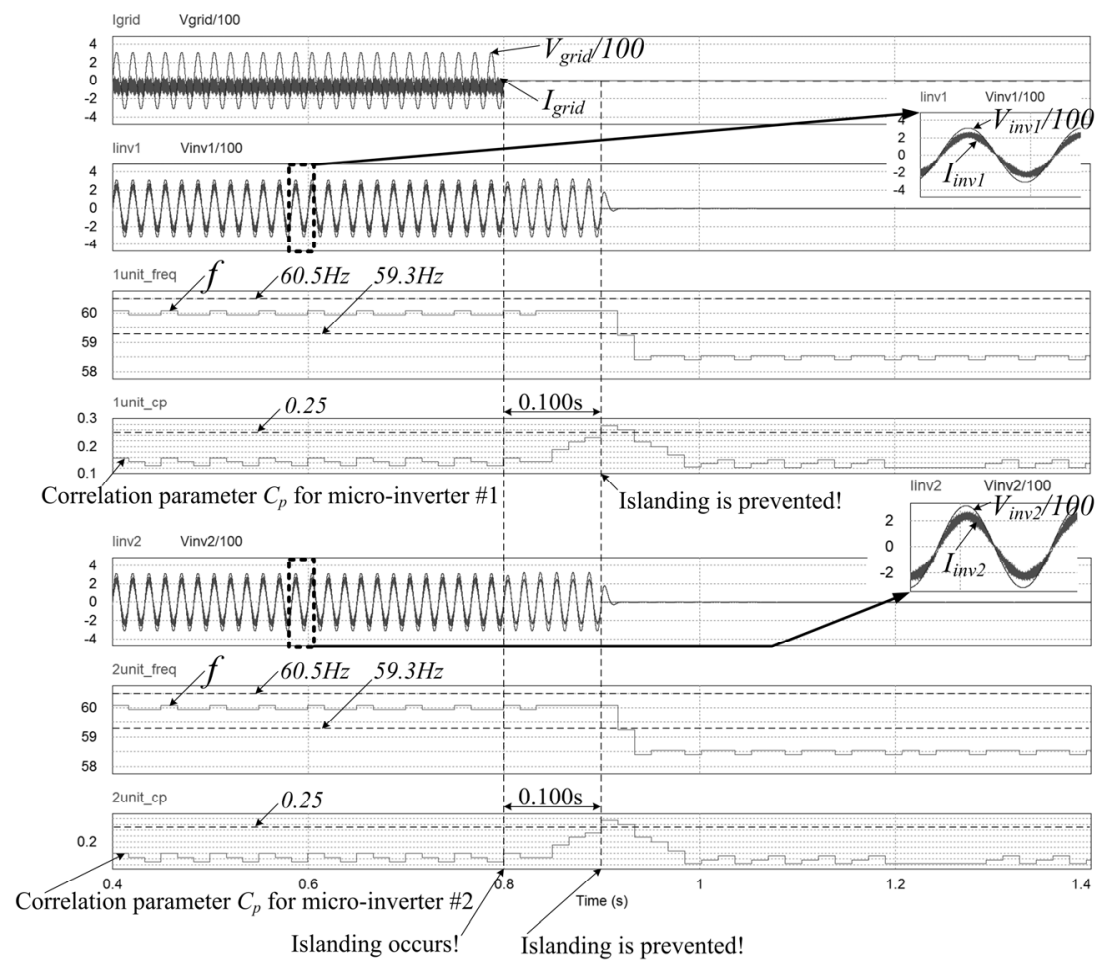

(b)

Fig. 8. Anti-islanding test results by using the proposed AFD method under unity quality factor local resonant load. (a) $\left(c f_{p}=+2.5 \%, c f_{n}=-2.5 \%\right)$ chopping fraction injection for single micro inverter. (b) $\left(c f_{p}=+2.5 \%, c f_{n}=-2.5 \%\right)$ chopping fraction injection for two micro inverter. 
current $\left(I_{\text {grid }}\right)$, and micro inverter output current $\left(I_{\text {inv }}\right)$, the scaled inverter output voltage $\left(V_{i n v} / 100\right)$, and the frequency $(f)$ of micro inverter output voltage in Fig. 1. As shown in Fig. 7 (a), islanding by using the conventional AFD method with $+5 \%$ chopping fraction is prevented at $0.097 \mathrm{~s}$ by deviating the frequency over $60.5 \mathrm{~Hz}$ after islanding occurs, which meets IEEE Std. 1547 requirement that islanding should be prevented within $2 \mathrm{~s}$. As another single unit anti-islanding test, the conventional AFD method with $-5 \%$ chopping fraction prevents islanding at $0.102 \mathrm{~s}$ by drifting the frequency less than $59.3 \mathrm{~Hz}$ after islanding in Fig. 7 (b), which is also satisfied. However, for two-unit micro-inverter systems, as shown in Fig. 7 (c), islanding is not detected at all because of the cancellation effect between two different AFD methods: one is based on $+5 \%$ chopping fraction for micro-inverter $\# 1$ and the other is on $-5 \%$ chopping fraction for micro-inverter\#2 in Fig. 6.

Fig. 8 shows the simulation results by using the proposed AFD method with $\left(c f_{p}=+2.5 \%, c f_{n}=-2.5 \%\right)$ based on correlation parameter. As a single unit anti-islanding test result in Fig. 1, Fig. 8 (a) shows the waveforms of individual voltage/current waveforms like $V_{\text {grid }}, I_{\text {grid }}, I_{i n v}, V_{\text {inv }} / 100$, and $f$ in addition to the calculated correlation parameter $C_{P}$. As show in Fig. 8 (a), the dc component of micro-inverter output $\mathrm{AC}$ current $\left(I_{i n v, d c}\right)$ is very small by the revised current magnitude command in the section 3.1. After islanding occurs, the frequency f doesn't deviate enough over OFR or UFR, but the proposed calculated parameter starts to increase over the threshold value 0.25 and islanding is confirmed at $0.099 \mathrm{~s}$ after it occurs. This is because the half-line frequency in equation (6) is fixed by the concrete utility voltage source when the grid is connected and it is deviated by the proposed AFD method when islanding occurs. In addition, the proposed AFD method was also tested for two micro-inverter systems, as shown in Fig. 8 (b). Unlike the conventional AFD method, the proposed AFD method always injects \pm chopping fraction $\left(c f_{p}\right.$ and $\left.c f_{n}\right)$ every half-line cycle without any cancellation between them by using the half-line cycle of the utility voltage as a reference. Thus, as shown in Fig. 8 (b), the proposed AFD method detects islanding at $1 \mathrm{~s}$ after islanding occurs without cancellation effect even though two micro-inverters are connected. The proposed AFD method shows the highly effective islanding detection capability under both single unit and multi-unit systems.

\section{Conclusion}

This paper presents an improved AFD anti-islanding method for multiple PV micro-inverter systems. The proposed method injects every half-line cycle asymmetrical signals and uses the correlation between the injected asymmetrical signal and the corresponding half line cycle. From the analysis and the simulation result, it is verified that the proposed method is highly effective to detect islanding even under multiple micro-inverter system by using the utility voltage as reference to avoid cancelation effect while the conventional one doesn't detect islanding.

\section{Acknowledgments}

This work was supported by the New \& Renewable Energy of the Korea 
Institute of Energy Technology Evaluation and Planning (KETEP) grant funded by the Korea government Ministry of Knowledge Economy. (No. 20123010010060) and by the Human Resources Program In Energy Technology of the Korea Institute of Energy Technology Evaluation and Planning (KETEP) granted financial resource from the Ministry of Trade, Industry \& Energy, Republic of Korea (NO. 20134010200540). 